Note: This is a pre-copy-editing, author-produced PDF of an article accepted for publication in Addiction following peer review. The definitive publisher-authenticated version [Johnson Z, O'Connor M., Pomeroy L, Johnson H., Barry J, Scully M, \& Fitzpatrick E, (1994), Prevalence of HIV and associated risk behaviour in attendees at a Dublin needle exchange, Addiction, 89(5), 1994, 603-607] is available to purchase online at http://www3.interscience.wiley.com/journal/119282356/abstract

\title{
Prevalence of HIV and associated risk behaviour in attendees at a Dublin needle exchange
}

\author{
Z. JOHNSON, M. O'CONNOR, L. POMEROY, H. JOHNSON, J. BARRY, M. SCULLY \& E. \\ FITZPATRICK
}

Published in Addiction, 89(5), 1994, pp.603-607

Copyright: Wiley-Blackwell

\begin{abstract}
The aim of this study was to measure the prevalence of HIV infection and assess the level of equipment- sharing and unsafe sexual activity among attendees at a Dublin needle exchange. Using an anonymous unlinked approach, attendees were asked to complete a brief questionnaire and provide a sample of saliva for HIV testing. Of the 144 attendees eligible for inclusion during the study period, 106 agreed to participate and complete a questionnaire, a response rate of $74 \%$. Of the 81 respondents who submitted a usable saliva sample, $14.8 \%$ were HIV positive. Half of the respondents claimed that they had not shared equipment during the preceding 28 days, but a third had shared with multiple partners. Half of the respondents claimed that they had multiple sexual partners during the preceding year, but only a quarter said that they always used condoms. The prevalence of HIV infection is similar to that found $m$ routine linked testing of drug users in Ireland. The high level of unsafe injecting and sexual activity makes clear the need for more effective health promotion among drug users in Dublin.
\end{abstract}

\section{Introduction}

Ireland has a much higher proportion of HIV transmission due to intravenous drug abuse than is the case in many other European countries, and a large proportion of this problem occurs in Dublin. Over $40 \%$ of AIDS cases in Ireland are associated with intravenous drug abuse $^{1}$. In order to address this situation, the Eastern Health Board set up a needleexchange programme in mid-1989. The response in terms of the number of people attending the exchange was good. By the end of 1990 approximately 630 individuals had attended the exchange and there had been approximately 3200 attendances in all. At this stage it was felt necessary to evaluate the exchange in a more formal way. The aim of this study was to measure the prevalence of HIV infection and assess the level of equipmentsharing and unsafe sexual activity among attendees at a Dublin needle exchange. This data will provide a baseline for on-going monitoring of the effect of the needle-exchange service.

\section{Methods}

Using a protocol devised by the Public Health Laboratory Service AIDS Centre, Colindale, London, ${ }^{2}$ all attendees at the exchange during a 6-week period in February-March 1991 were asked to supply a sample of saliva for HIV testing and to complete a brief selfadministered questionnaire. Participation was voluntary and both saliva and questionnaire were anonymous but linked together by a common code number. This study design meant 
that it was not possible to attribute the results of HIV testing to individuals, but serological testing with full counselling was available for people wishing to find out their antibody status.

The one-page questionnaire included questions on age, sex, previous HIV testing, frequency of injecting, drugs used, needle and syringe sharing, number of sexual partners and condom usage. HIV testing was via y antibody capture enzyme-linked immunosorbent assay (GAC ELISA) capture. The test materials were from prototype kits supplied by Dr J. Parry, Virus Reference Laboratory, Public Health Laboratory Service, Colindale.

Statistical analysis was done using the SAS® System, Version 6.06 (SAS Institute, Cary, North Carolina). The chi-squared test was used for comparison of proportions and the Wilcoxon rank sum test was used for comparison of medians. Student's t-test was used for comparing means. Differences not significant at the $5 \%$ level are indicated by (NS).

During the study period, 144 people attending the centre were eligible for inclusion in the study and 106 participated, a response rate of $74 \%$. All clients attending the centre during the study period were eligible for inclusion provided that they had not previously been asked to participate - thus the only exclusion criterion was having participated or declined to participate on a prior occasion during the study period.

\section{Results}

Table 1. Needle-sharing behaviour of respondents during month preceding survey

\begin{tabular}{lllll}
\hline \multirow{2}{*}{ Needle-lending practices } & \multicolumn{3}{c}{ Needle-borrowing practices } \\
\cline { 2 - 5 } & None & 1 partner & 2 or more partners & Total \\
\hline None & $35(46.1 \%)$ & $4(5.3 \%)$ & $1(1.3 \%)$ & $40(52.6 \%)$ \\
1 partner & $2(2.6 \%)$ & $7(9.2 \%)$ & $1(1.3 \%)$ & $10(13.2 \%)$ \\
2 or more partners & $2(2.6 \%)$ & $0(0.0 \%)$ & $24(31.6 \%)$ & $26(34.2 \%)$ \\
Total & $39(51.3 \%)$ & $11(14.5 \%)$ & $26(34.2 \%)$ & $76(100.0 \%)$ \\
\hline
\end{tabular}

Percentages refer to percentage of the total (76).

Sex of respondent was available on 104 cases, 80 males and 24 females (male-female ratio was 3.3:1). The median age of the males was 28 years (range 18-40) and that of females was 27 (range 19-36). The median age of starting to inject drugs was 19 (range $6-36)$. The drug used most often during the 28 days preceding the survey was MST (morphine sulphate)-it had been used by $48.1 \%$ of respondents. Next most frequent was heroin, which had been used by $34.9 \%$. Of the 106 persons who participated in the study, 76 responded to questions on needle-sharing while 30 did not. There was a similar proportion of males among responders $57 / 76$ (75\%) and non-responders 24/29 (82.8\%) (NS). The mean age of responders was 29.0 years and that of non-responders was 29.8 years (NS). The mean age of starting intravenous drug use was 20.1 years for responders and 25.7 years for non-responders (NS).

Table 1 shows the needle-sharing practices during the month preceding the survey of the 76 respondents who replied to the questions on sharing. Of these, nearly half shared with no one else but over a third shared with two or more other people. Although $27 / 60(45 \%)$ of males reported no sharing of needles compared with $11 / 20(55 \%)$ of females this difference was not statistically significant. As regards age, 22/53 (41.5\%) of respondents aged under 30 reported no sharing compared with 15/26 (57.7\%) of those aged over 30 (NS). Table 1 distinguishes between needle-lending and needle-borrowing. Of the 40 respondents who claimed not to have lent needles during the preceding month, 5 or $12.5 \%$ had borrowed from others. Of the 39 who claimed not to have borrowed during the preceding month, four (10.3\%) had lent needles to others. 
Table 2. Condom-usage of respondents in relation to HIV status

\begin{tabular}{lcccccc}
\hline & \multicolumn{2}{c}{ Positive } & \multicolumn{2}{c}{\begin{tabular}{c} 
HIV status \\
\multicolumn{2}{c}{ Negative }
\end{tabular}} \\
\cline { 2 - 7 } Condom usage & $\mathrm{n}$ & $(\%)$ & $\mathrm{n}$ & $(\%)$ & $\mathrm{n}$ & $(\%)$ \\
\hline Always & 3 & $(30.0)$ & 14 & $(23.3)$ & 17 & $(24.3)$ \\
Sometimes & 5 & $(50.0)$ & 26 & $(43.3)$ & 31 & $(44.3)$ \\
Never & 2 & $(20.0)$ & 20 & $(33.3)$ & 22 & $(31.4)$ \\
Total & 10 & $(100.0)$ & 60 & $(100.0)$ & 70 & $(100.0)$ \\
\hline
\end{tabular}

$X^{2}=0.73(2 \mathrm{df}) \mathrm{p}=0.7$.

As regards sexual activity, respondents were asked the following question: in the last year, have you had sexual intercourse (vaginal or anal)? Some 99 respondents answered the question and 92 of these (92.9\%) had seen sexually active during the preceding year. Those who answered yes to the above question were asked the following questions: if yes, with how many different men? and with how many different women? Seventy-six respondents provided information on their number of sexual partners. Forty-one of these $(53.9 \%)$ claimed to have had one partner only and $35(46.1 \%)$ claimed to have had more than one. Of the 19 male respondents who answered the question on number of male partners, two claimed that they had had one or more male partners during the preceding year.

As regards condom use, 88 respondents answered the question but only $21(23.9 \%)$ claimed to use condoms always, with 41 (46.6\%) using them sometimes and $26(29.5 \%)$ never using them.

A usable sample of saliva was obtained from 81 respondents and of these $12(14.8 \%)$ were HIV positive. Eighteen per cent of males (11/61) and $5.3 \%$ of females (1/19) were HIV positive (NS). As regards age group, $14.8 \%(8 / 54)$ of those under 30 were HIV positive compared with $16 \%(4 / 25)$ of those over 30 (NS).

Seventy-seven of those tested for HIV answered the question on sexual intercourse during the preceding year. Of the HIV positive cases, 10/11 had been sexually active compared with $60 / 66$ of those who were HIV negative (NS).

Fifty-nine of those tested for HIV answered the question on number of sexual partners during the preceding year. Of those HIV positive and sexually active, 5/9 (55.5\%) had had more than one partner compared with $20 / 50$ (40.0\%) of those who were HIV negative (NS).

Seventy of those tested for HIV answered the question on condom use and Table 2 reveals that only $30 \%$ of those who were HIV positive claimed to have used condoms always.

Table 3 shows that $80 \%$ of HIV positive respondents shared needles compared with $51 \%$ of HIV negatives (NS). The median number of years since commencement of injecting drugs was 9 for both HIV positive and HIV negative respondents (NS). 
Table 3. Needle-sharing practices of respondents in relation to HIV status

\begin{tabular}{lcccccc}
\hline & \multicolumn{2}{c}{ Positive } & \multicolumn{2}{c}{ HIV status } & \multicolumn{2}{c}{ Negative } \\
No. of sharing partners & $\mathrm{n}$ & $(\%)$ & $\mathrm{n}$ & $(\%)$ & $\mathrm{n}$ & $(\%)$ \\
\hline None & 2 & $(20.0)$ & 26 & $(49.0)$ & 28 & $(44.4)$ \\
1 partner & 2 & $(20.0)$ & 9 & $(17.0)$ & 11 & $(17.5)$ \\
2 or more partners & 6 & $(60.0)$ & 18 & $(34.0)$ & 24 & $(38.1)$ \\
Total & 10 & $(100.0)$ & 53 & $(100.0)$ & 63 & $(100.0)$ \\
\hline
\end{tabular}

$X^{2}=3.14(2 d f) p=0.2$.

\section{Discussion}

This is the first anonymous unlinked study of HIV prevalence among Irish intravenous drug users, and also the first Irish study to employ salivary testing. The response rate of $74 \%$ was reasonably good, but the fact that a usable sample of saliva was only obtained from 81 people (76\% of respondents but $56 \%$ of attendees) was disappointing as intensive efforts were made by the staff to recruit as many attendees as possible. Every attempt was made to reassure them about the anonymous unlinked nature of the study, and to explain clearly the saliva collection procedure.

Our results suggest that approximately one person in six attending the Dublin exchange was HIV positive, a level similar to that revealed by routine linked HIV testing of drug users in Ireland. This finding should be regarded with some caution in the light of the relatively poor uptake of saliva testing among the total sample. It is possible that attendees who knew themselves

to be HIV positive might have been less likely to participate in the study or to provide a usable sample of saliva, and thus the true prevalence of HIV may be substantially higher than $14.8 \%$. If the 63 drug users who attended the needle- exchange during the study period but failed to submit a saliva sample were all HIV positive, then the seroprevalence could be as high as 52\%. On the other hand, if they were all negative the seroprevalence would be $8.3 \%$. However, the prevalence of HIV antibodies in this population is definitely higher than the rate of $2.4 \%$ found in a study carried out at a needle-exchange in London which employed a similar methodology to ours ${ }^{3}$ but which had a response rate of $89 \%$. In Edinburgh in 1988 it was found that $36.5 \%$ of 104 intravenous drug users attending the Community Drug problem Service were HIV positive. However, less than half of all attendees were tested. ${ }^{4}$ A city-wide study in Edinburgh involving HIV testing of saliva from 226 drug users found $20.4 \%$ to be HIV positive. ${ }^{5}$ in Dundee, five out of 13 known drug users (38.5\%) in a necropsy series were HIV positive. ${ }^{6}$ In 1990 a large study involving over 500 drug users in Glasgow and using saliva testing found that $1.1 \%$ were HIV positive. The response rate in this study was over $90 \%{ }^{7}$

Although we have no information as to when HIV infection may have occurred among those found to be HIV positive, the fact that respondents, both HIV positive and HIV negative, reported recent unsafe needle and sexual practices is disturbing and suggests that the virus may continue to spread at a significant rate among the attendees and their contacts. Needle/syringe-sharing is especially dangerous, ${ }^{8}$ and the fact that $60 \%$ of HIV positive respondents and $34 \%$ of HIV negative respondents had recently shared equipment with two or more partners, despite freely available clean works and intensive counselling must cause serious concern. However, it is quite possible that an even higher level of needle-sharing would prevail if the exchange did not exist. It is encouraging to note that $46.1 \%$ of respondents in our study reported no equipment-sharing as compared to $36 \%$ of those in the London study. ${ }^{3}$ However, a lower reported prevalence of needle- 
sharing in Glasgow (7\%) than in Dublin may help to explain why HIV prevalence among drug users in that city appears to be much lower than in Dublin. ${ }^{7}$ Needle- sharing seems to be declining in Edinburgh, ${ }^{5,9,10}$ and we hope to repeat our study in 1994 in order to see whether a similar trend is occurring in Dublin.

The finding that nearly half of the respondents (46.1\%) and $55.5 \%$ of those who were HIV positive, claimed to have had more than one sexual partner during the preceding 12 months is also disturbing. The risk of getting HIV infection via sexual contact is somewhat lower than that from equipment-sharing but is nevertheless very substantial. ${ }^{8}$ In the London study $25 \%$ of respondents reported multiple sexual partners, but the question referred only to the 3 months prior to the study. ${ }^{3}$

A quarter of the respondents in our study reported using condoms always, but a third never used them. This level of usage is fairly similar to that found among drug users in New York, ${ }^{11}$ and while it may slow down the sexual transmission of HIV infection, it will certainly not eliminate it. A recent review of condoms usage suggested that the attitude of the French essayist de Montaigne who in the 16th century described condoms as "armour against enjoyment, gossamer against infection" is still the predominant view today. ${ }^{12}$ However, it was suggested that these attitudes may be modifiable, especially by health professionals.

Despite the limitations of the present study, it does provide a valuable snapshot of the level of HIV infection and risk behaviour among needle-exchange attendees in Dublin. Its most import- ant benefit will be to provide a baseline against which the effectiveness of the needle-exchange can be measured by carrying out periodic studies using the same methodology. It also shows the need for new and more effective strategies designed to promote safer drug usage and sexual activity among drug users.

\section{Acknowledgements}

We sincerely thank the following who contributed in various ways to the study: all the staff of the needle-exchange centre, including Ms Mary Warde, Mr David Wyse, Ms Mary O'Neill, Ms Teresa O'Mahoney, Mr Thomas Keams and Ms Aine Cosgrove. We also thank Ms Aine Flanagan of the Eastern Health Board, Professor Irene Hillery and Dr Geraldine Kaminsky of the Virus Reference Laboratory of University College Dublin, Dr John V. Parry and Ms Amanda Durante of the Public Health Laboratory Service, Colindale and Dr Harold Brenner of the North Western Health Board, Sligo.

\section{References}

1. BRENNER, H., HERNANDO-BRIONGOS, P. \& Goos, C. (1991) AIDS among drug users in Europe, Drug and Alcohol Dependence, 29, pp. 171-181.

2. JOCE, R., DURANTE, A. J., GILL, O. N., MORTIMER, P. P., PARRY, J. V., CONNELL, J. A. \& PERRY, K. R. (1990) Collaborative study of the prevalence of HIV antibody and antibody to hepatitis B core antigen in the saliva of injecting drug users (London, PHLS AIDS Centre, CDSC, Colindale).

3. HART, G. J., WOODWARD, N., JOHNSON, A. M., TIGHE, J., PARRY, J. V. \& ADLER, M. W. (1991) Prevalence of HIV, hepatitis B and associated risk behaviours in clients of a needle-exchange in central London, AIDS, 5, pp. 543-547.

4. GREENWOOD, J. (1990) Creating a new drug service in Edinburgh, British Medical Journal, 300, pp. 587-589. 
5. BATH, G. E., DOMINY, N., BURNS, S. M., PETERS, A., DAVIES, A. G. \& RICHARDSON, A. M. (1993) Fewer drug users share needles, British Medical Journal, 306, p. 1414 (letter).

6. SADLER, D. W., POUNDER, D. J., URQUHART, G. E. D. \& PORTER-BOVERI, M. (1992) British Medical Journal, 304, pp. 1027-1028.

7. FRISCHER, M., GREEN, S. T., GOLDBERG, D. J., HAW, S., BLOOR, M., MCKEGANEY, N., COVELL, R., TAYLOR, A., GRUERS, L. D., KENNEDY, D., FOLUETT, E. A. \& EMSUE, J. A. (1992) Estimates of HIV infection among injecting drug users in Glasgow, 1985-1990, AIDS, 6, 1371-1375.

8. NICOLOSI, A., LEITE, M. L., Musicco, M., MOLINARI, S. \& LAZZARIN, A. (1992) Parenteral and sexual transmission of HIV in intravenous drug users: a study of seroconversion. The Northern Italian Seronegative Drug Addicts (NISDA) Study, American Journal of Epidemiology, 135, pp. 225-233.

9. RONALD, P.J.M., ROBERTSON, J.R. \& ROBERTS, J.J.K. (1992) Risk taking behaviour on the decline in intravenous drug users, British Journal of Addiction, 87, pp. 115116.

10. GRIFFIN, S., PETERS, A. \& REID, M. (1993) Drug misusers in Lothian: changes in injecting habits 1988-90, British Medical Journal, 306, p. 693.

11. CENTRES FOR DISEASE CONTROL (1992) Condom use among male injecting drug users-New York City, 1987-1990, Morbidity and Mortality Weekly Report, 41, pp. 617-620.

12. Ross, M. W. (1992) Attitudes toward condoms and condom use: a review, International Journal of STD and AIDS, 3, pp. 10-16. 